\title{
Does Vitamin D Deficiency Correlates with Metabolic Syndrome in Egyptian Population
}

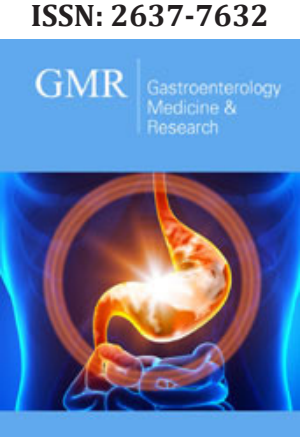

*Corresponding author: Aya Mohammed Mahros, Lecturer at Department of Hepatology, Gastroenterology and infectious disease Faculty of Medicine, Kafrelsheikh University, Egypt

Submission: 酱 December 17, 2020

Published: 留 February 17, 2021

Volume 5 - Issue 4

How to cite this article: Rasha Ibrahem Salama, Aya Mohamed Mahros. Does Vitamin D Deficiency Correlates with Metabolic Syndrome in Egyptian Population. Gastro Med Res. 5(4). GMR. 000618. 2021.

DOI: 10.31031/GMR.2021.05.000618

Copyright@Aya Mohammed Mahros This article is distributed under the terms of the Creative Commons Attribution 4.0 International License, which permits unrestricted use and redistribution provided that the original author and source are credited.

\section{Rasha Ibrahem Salama ${ }^{1}$ and Aya Mohamed Mahros ${ }^{2 *}$ \\ ${ }^{1}$ Assistant consultant, Department of Tropical Medicine, Faculty of Medicine, Zagzig University, Egypt}

${ }^{2}$ Lecturer at Department of Hepatology, gastroenterology and infectious diseases, Faculty of Medicine, Kafrelsheikh University, Egypt

\begin{abstract}
Background: Metabolic syndrome (MS) has become a serious health problem worldwide and it is a major cause of morbidity and mortality especially from cardiovascular diseases. Different factors involved in pathogenesis like environmental, genetic, and sedentary life. Recent studies demonstrates that Vitamin D3 deficiency has a growing role in pathogenesis of MS. Many studies had addressed the relationship between serum Vitamin D3 and metabolic syndrome but to the best of our knowledge, few studies about this relationship in Egyptian population.
\end{abstract}

Aims: To assess the relationship between deficiency of Vitamin D3 with metabolic syndrome in Egyptian population.

Patients and methods: This is cross sectional study invite 200 participants from healthy clubs but only 180 accept to participate. According to the presence or absence of metabolic syndrome, our participant were divided into two groups. All participants were subjected to detailed medical history, clinical and anthropometric assessment, and laboratory analysis including serum Vitamin D3 level.

Result: The mean age of the studied patients was $40.91 \pm 8.72$, and majority were female $(66.7 \%)$. Metabolic syndrome cases were significantly higher as regard the age, SBP, DBP, TG, FBS, WC and BMI but significantly lower regard HDL and Vitamin D3, and no significant association with sex. Vitamin D deficiency cases were significantly higher as regard Age, SBP, DBP, TG, FBS, WC and BMI but sig lower regard HDL. There was significant different between patients with and without Vitamin D3 deficiency as regard the presence of metabolic syndrome $(P$ value $=.00)$. There was moderate negative correlation between Vitamin D3 deficiency and age, SBP, DBP, FBS, WC and BMI with positive weak correlation with HDL level. Vitamin D3 deficiency $<20 \mathrm{ng} / \mathrm{ml}$ and BMI $>35$ were significant predictors for metabolic syndrome with (P value $0.00,0.04$ ) respectively.

Conclusion: Vitamin D3 level inversely correlates with the presence of metabolic syndrome in Egyptian Population

Keywords: Metabolic syndrome; Vitamin D deficiency

\section{Introduction}

Metabolic syndrome (MS) has become a major health problem worldwide and it is a major cause of morbidity and mortality especially from cardiovascular diseases. Hypertension, dyslipidemia, hyperglycemia, insulin resistance, abdominal obesity is major component of MS [1]. Factors involved in pathogenesis of MS includes environmental, genetic, and sedentary life [2]. Vitamin D deficiency has a growing role in pathogenesis of MS [3]. A strong relationship of Vitamin $\mathrm{D}_{3}$ deficiency and the degree of obesity especially central one may be related to insufficient sun exposure and outdoor activities [4]. Vitamin $\mathrm{D}_{3}$ deficiency inversely affects the insulin secretion [5]. Many studies reported that the lower level of Vitamin $\mathrm{D}_{3}$ induce the development of insulin resistance and thus Type 2 DM by decreasing insulin sensitivity [6]. Vitamin $\mathrm{D}_{3}$ deficiency have been reported to upregulate the renin-angiotensin-aldosterone system (RAAS), resulting in systolic and diastolic hypertension [7]. Many studies addressed risk factors for MS, but there are few studies on the role of Vitamin $\mathrm{D}_{3}$ deficiency on MS especially in Egyptian population.

\section{Aim of study}

Our study aimed assess the relationship between deficiency of Vitamin D with metabolic syndrome in Egyptian population. 


\section{Patients and Methods}

Our cross sectional study invite 200 subjects from healthy clubs at Kafrelsheikh and Zagzig governorate, Egypt. However, 180 only were enrolled into the study as 20 patients did not attend their appointment for the laboratory tests. The criteria for inclusion in the study were any sex, or age, and participant were divided into two groups according to presence or absence of MS. The exclusion criteria were refusal to participate and Vitamin D supplementation. All participants were subjected to detailed medical history, clinical and anthropometric assessment, and laboratory analysis. MS was diagnosed if the patient had at least 3 out of 5 of its components, in accordance with the modified criteria proposed by the IDF in 2009 . These includes waist circumference $\geq 80 \mathrm{~cm}$, fasting glycemia $\geq 100 \mathrm{mg} / \mathrm{dL}$, triglyceride level $\geq 150 \mathrm{mg} / \mathrm{dL}$, HDL cholesterol level $<50 \mathrm{mg} / \mathrm{dL}$, and elevated blood pressure (sBP $\geq 130$ and/or $\mathrm{dBP} \geq 85 \mathrm{mmHg}$ ) or related therapies to any of above conditions [8]. A digital scale were used to assess anthropometric measurements. Waist circumference was measured midway between the upper margin of the iliac crest and the lower rib margin. We considered a waist circumference $\leq 80$ Body mass index (BMI) in the range of $18.5-24.9 \mathrm{~kg} / \mathrm{m}^{2}$ as normal, and between $25.0 \mathrm{~kg} /$ $\mathrm{m}^{2}$ and $29.9 \mathrm{~kg} / \mathrm{m}^{2}$ denoted overweight, and $\mathrm{I} \geq 30 \mathrm{~kg} / \mathrm{m}^{2}$ indicated obesity. Blood pressure was measured using a manual manometer in a semi sitting participant after adjusting the cuff according to arm circumference at the heart level. Fasting blood samples were withdrawn for biochemical assessment: serum cholesterol, high density lipoprotein (HDL), triglycerides (TG,), and Vitamin $\mathrm{D}_{3}$. Vitamin $\mathrm{D}_{3}$ was measured by competitive radioimmunoassay kits (Cobas $^{\circledR}$; Roche Vitamin D Total first generation assay (250HD-I), Roche Diagnostics, Indianapolis, IN, USA).

\section{Ethics and consent}

The study was approved by the Faculty's ethics committee and permission was obtained from all departmental heads who ensured confidentiality was maintained and ethical principles were followed. Prior to participation in the study, the background and reasons for conducting the study were explained and prospective patients were not obliged to participate. Written informed consent was obtained from all participants

\section{Statistical analysis}

Statistical analysis was performed by using statistical package for social sciences (SPSS) version 22.0. Descriptive statistics was presented as proportion, Mean \pm standard deviation (SD) and median with interquartile range. Comparative analysis was done by $\chi^{2}$ test. A P-value less 0.05 was considered significant.

\section{Results}

We initially invited 200 subjects, however, 180 only were enrolled into the study as 20 patients did not attend their appointment for the laboratory tests. The mean age of the studied patients was $40.91 \pm 8.72$, and majority were female $(66.7 \%)$. Metabolic syndrome was present in 60 participants (33.3\%) while Vitamin $\mathrm{D}_{3}$ deficiency was present in 80 participants (44.4\%) (Table 1). Table 2 show that metabolic syndrome cases were significantly higher as regard the age, SBP, DBP, TG, FBS, WC and BMI but significantly lower regard HDL and Vitamin $\mathrm{D}_{3}$, and no significant association with sex. Table 3 show there was significant different between patients with and without Vitamin $\mathrm{D}_{3}$ deficiency as regard the presence of metabolic syndrome $\mathrm{P}$ value $=.00$ with $95 \%$ confidence interval at 56(18.4-169.6). Significant association and significant risk between VD deficiency and MS. Table 4 show that Vitamin $D_{3}$ deficiency cases were significantly higher as regard Age, SBP, DBP, TG, FBS, WC and BMI but significantly lower regard HDL and no significant association with sex. Table 5 show a spearman correlation analysis was run to determine the relationship between Vitamin $\mathrm{D}_{3}$ deficiency and variable risk factors'. There was moderate negative correlation between Vitamin D deficiency and age, SBP, DBP, FBS, WC and BMI. ( $r=$. -0.495), $(r=-0.610),(r=-0.661),(r=-$ $0.622),(r=-0.692),(r=-0.632),(r=-0.617),(r=-0.617)$ respectively and positive weak correlation with HDL level $(r=.339)$. Table 6 show multivariate logistic regression for independent predictors of metabolic syndrome demonstrate that Vitamin $\mathrm{D}_{3}$ deficiency $<20 \mathrm{ng} / \mathrm{ml}$ and $\mathrm{BMI}>35$ were significant predictors with (P value $0.00,0.04)$ respectively, while we found Age $>42$ were insignificant one ( $\mathrm{p}$ value=.22) for metabolic syndrome.

Table 1: Age and sex distribution among studied group.

\begin{tabular}{|c|c|c|}
\hline \multicolumn{2}{|c|}{ Age } \\
\hline \multicolumn{2}{|c|}{ Mean \pm SD } & $40.91 \pm 8.72$ \\
\hline \multicolumn{2}{|c|}{ Median (Range) } & $42.0(18-52)$ \\
\hline \multirow{2}{*}{ Sex } & & N (\%) \\
\hline \multirow{2}{*}{ Metabolic syndrome } & Male & $60(33.3)$ \\
\cline { 2 - 3 } & Female & $120(66.7)$ \\
\hline \multirow{2}{*}{ Vitamin $D_{3}$} & Positive & $60(33.3)$ \\
\cline { 2 - 3 } & Negative & $120(66.7)$ \\
\cline { 2 - 3 } & Normal & $100(55.6)$ \\
\cline { 2 - 3 } & Deficient & $80(44.4)$ \\
\hline
\end{tabular}


Table 2: Comparison between metabolic and non-metabolic syndrome.

\begin{tabular}{|c|c|c|c|c|c|}
\hline & & & No & Metabolic & $\mathbf{P}$ \\
\hline \multicolumn{3}{|c|}{ Age } & $38.3 \pm 8.95$ & $46.13 \pm 5.28$ & $0.00^{* *}$ \\
\hline \multicolumn{3}{|c|}{ SBP } & $117.33 \pm 8.95$ & $136.66 \pm 5.42$ & $0.00^{* *}$ \\
\hline \multicolumn{3}{|c|}{ DBP } & $77.66 \pm 5.90$ & $87.66 \pm 2.51$ & $0.00^{* *}$ \\
\hline \multicolumn{3}{|c|}{ TG } & $122.86 \pm 22.43$ & $181.66 \pm 14.69$ & $0.00^{* *}$ \\
\hline \multicolumn{3}{|c|}{ FBS } & $96.86 \pm 9.43$ & $116.33 \pm 6.5$ & $0.00^{* *}$ \\
\hline \multicolumn{3}{|c|}{ HDL } & $55.3 \pm 7.51$ & $47.86 \pm 6.19$ & $0.00^{* *}$ \\
\hline \multicolumn{3}{|c|}{$\mathrm{WC}(\mathrm{cm})$} & $86.73 \pm 7.07$ & $98.93 \pm 6.15$ & $0.00^{* *}$ \\
\hline \multicolumn{3}{|c|}{ Vitamin $\mathrm{D}_{3}$} & $27.43 \pm 8.34$ & $17.6 \pm 6.85$ & $0.00^{* *}$ \\
\hline \multicolumn{3}{|c|}{ BMI } & $29.5 \pm 4.11$ & $36.66 \pm 2.13$ & $0.00^{* *}$ \\
\hline \multirow{2}{*}{ Sex } & Male & N (\%) & $37(30.8 \%)$ & $23(38.3 \%)$ & \multirow{2}{*}{0.31} \\
\hline & Female & $\mathrm{N}(\%)$ & $83(69.2 \%)$ & $37(61.7 \%)$ & \\
\hline
\end{tabular}

SBP: Systolic Blood Pressure, DBP: Diastolic Blood Pressure, TG: Triglyceride, FBS: Fasting Blood Sugar, HDL: High Density Lipoprotein, WC: Waist Circumference, BMI: Body Mass Index.

Table 3: Association and risk assessment between metabolic syndrome and Vitamin D deficiency.

\begin{tabular}{|c|c|c|c|c|c|}
\hline & & \multicolumn{2}{|c|}{ Metabolic Syndrome } & \multirow{2}{*}{$P$ Value } & \multirow{2}{*}{ OR (CI 95.0\%) } \\
\hline \multicolumn{2}{|c|}{ No } & Metabolic & & & \\
\hline \multirow{4}{*}{ Vitamin $D_{3}$ Deficiency } & No & \multirow{2}{*}{$96(80.0 \%)$} & \multirow{2}{*}{$4(6.7 \%)$} & & \\
\hline & N (\%) & & & & \\
\hline & Yes & \multirow{2}{*}{$24(20.0 \%)$} & \multirow{2}{*}{$56(93.3 \%)$} & $0.00^{* *}$ & \\
\hline & $\mathrm{N}(\%)$ & & & & $56(18.4-169.6)$ \\
\hline \multicolumn{2}{|c|}{ Total } & $120(100 \%)$ & $60(100 \%)$ & & \\
\hline
\end{tabular}

\begin{tabular}{|c|c|c|c|c|c|c|}
\hline & & & No Vitamin $D_{3}$ Deficiency & Vitamin D Deficiency & $t / X^{2}$ & $\mathbf{P}$ \\
\hline \multicolumn{3}{|c|}{ Age } & $36.88 \pm 8.91$ & $45.95 \pm 5.18$ & 8.074 & $0.00^{* *}$ \\
\hline \multicolumn{3}{|c|}{ SBP } & $116.6 \pm 9.28$ & $132.75 \pm 8.78$ & 11.872 & $0.00^{* *}$ \\
\hline \multicolumn{3}{|c|}{ DBP } & $76.8 \pm 6.01$ & $86.25 \pm 3.51$ & 12.459 & $0.00^{* *}$ \\
\hline \multicolumn{3}{|c|}{$\mathrm{TG}$} & $119.44 \pm 21.47$ & $171.25 \pm 24.12$ & 15.222 & $0.00^{* *}$ \\
\hline \multicolumn{3}{|c|}{ FBS } & $94.84 \pm 8.65$ & $114.0 \pm 7.56$ & 15.6 & $0.00^{* *}$ \\
\hline \multicolumn{3}{|c|}{ HDL } & $55.72 \pm 8.18$ & $49.2 \pm 5.81$ & 6.014 & $0.00^{* *}$ \\
\hline \multicolumn{3}{|c|}{ WC } & $85.68 \pm 7.32$ & $97.2 \pm 6.09$ & 11.281 & $0.00^{* *}$ \\
\hline \multicolumn{3}{|c|}{ BMI } & $28.72 \pm 3.92$ & $35.85 \pm 2.64$ & 13.911 & $0.00^{* *}$ \\
\hline \multirow{4}{*}{ Sex } & \multirow{2}{*}{ Male } & $\mathrm{N}$ & 38 & 22 & & \\
\hline & & $\%$ & $38.00 \%$ & $27.50 \%$ & & \\
\hline & \multirow{2}{*}{ Female } & $\mathrm{N}$ & 62 & 58 & 2.21 & 0.13 \\
\hline & & $\%$ & $62.00 \%$ & $72.50 \%$ & & \\
\hline \multicolumn{2}{|c|}{ Total } & $\mathrm{N}$ & 100 & 80 & & \\
\hline \multicolumn{2}{|c|}{$\%$} & $100.00 \%$ & $100.00 \%$ & & & \\
\hline
\end{tabular}


Table 4: Relation with Vitamin D3 deficiency.

\begin{tabular}{|c|c|c|c|c|c|c|}
\hline & & & No Vitamin $D_{3}$ Deficiency & Vitamin D Deficiency & $t / X^{2}$ & $\mathbf{P}$ \\
\hline \multicolumn{3}{|c|}{ Age } & $36.88 \pm 8.91$ & $45.95 \pm 5.18$ & 8.074 & $0.00^{* *}$ \\
\hline \multicolumn{3}{|c|}{ SBP } & $116.6 \pm 9.28$ & $132.75 \pm 8.78$ & 11.872 & $0.00^{* *}$ \\
\hline \multicolumn{3}{|c|}{ DBP } & $76.8 \pm 6.01$ & $86.25 \pm 3.51$ & 12.459 & $0.00^{* *}$ \\
\hline \multicolumn{3}{|c|}{ TG } & $119.44 \pm 21.47$ & $171.25 \pm 24.12$ & 15.222 & $0.00^{* *}$ \\
\hline \multicolumn{3}{|c|}{ FBS } & $94.84 \pm 8.65$ & $114.0 \pm 7.56$ & 15.6 & $0.00^{* *}$ \\
\hline \multicolumn{3}{|c|}{ HDL } & $55.72 \pm 8.18$ & $49.2 \pm 5.81$ & 6.014 & $0.00^{* *}$ \\
\hline \multicolumn{3}{|c|}{ WC } & $85.68 \pm 7.32$ & $97.2 \pm 6.09$ & 11.281 & $0.00^{* *}$ \\
\hline \multicolumn{3}{|c|}{ BMI } & $28.72 \pm 3.92$ & $35.85 \pm 2.64$ & 13.911 & $0.00^{* *}$ \\
\hline \multirow{4}{*}{ Sex } & \multirow{2}{*}{ Male } & $\mathrm{N}$ & 38 & 22 & & \\
\hline & & $\%$ & $38.00 \%$ & $27.50 \%$ & & \\
\hline & \multirow{2}{*}{ Female } & $\mathrm{N}$ & 62 & 58 & 2.21 & 0.13 \\
\hline & & $\%$ & $62.00 \%$ & $72.50 \%$ & & \\
\hline \multicolumn{2}{|c|}{ Total } & $\mathrm{N}$ & 100 & 80 & & \\
\hline \multicolumn{2}{|c|}{$\%$} & $100.00 \%$ & $100.00 \%$ & & & \\
\hline
\end{tabular}

Table 5: Correlations between Vitamin D and other parameters.

\begin{tabular}{|c|c|c|}
\hline & & Vitamin D \\
\hline \multirow{2}{*}{ Age } & $\mathrm{r}$ & $-0.495^{* *}$ \\
\hline & $P$ & 0.000 \\
\hline \multirow{2}{*}{ SBP } & $\mathrm{r}$ & $-0.610^{* *}$ \\
\hline & $P$ & 0.000 \\
\hline \multirow{2}{*}{ DBP } & $\mathrm{r}$ & $-0.661^{* *}$ \\
\hline & $\mathrm{P}$ & 0.000 \\
\hline \multirow{2}{*}{$\mathrm{TG}$} & $\mathrm{r}$ & $-0.622^{* *}$ \\
\hline & $\mathrm{P}$ & 0.000 \\
\hline \multirow{2}{*}{ FBS } & $\mathrm{r}$ & $-0.692^{* *}$ \\
\hline & $\mathrm{P}$ & 0.000 \\
\hline \multirow{2}{*}{ HDL } & $\mathrm{r}$ & $0.339^{* *}$ \\
\hline & $\mathrm{P}$ & 0.000 \\
\hline \multirow{2}{*}{ WC } & $\mathrm{r}$ & $-0.632^{* *}$ \\
\hline & $P$ & 0.000 \\
\hline \multirow{2}{*}{ BMI } & $\mathrm{r}$ & $-0.617^{* *}$ \\
\hline & $P$ & 0.000 \\
\hline
\end{tabular}

Table 6: Multivariate logistic regression for independent predictors of MS.

\begin{tabular}{|c|c|c|c|c|c|}
\hline & \multirow{2}{*}{ Wald } & \multirow{2}{*}{$\mathbf{P}$} & \multirow{2}{*}{$\begin{array}{c}\text { OR } \\
\text { Lower } \\
\end{array}$} & \multicolumn{2}{|c|}{ 95\% C.I } \\
\hline & & & & Upper & \\
\hline Age $>42$ years & 1.488 & 0.222 & 1.057 & 0.967 & 1.156 \\
\hline VD3 <20 (ng/ml) & 3.92 & $0.042^{*}$ & 1.952 & 1.101 & 3.006 \\
\hline $\mathrm{BMI}>35$ & 30.204 & $0.00^{* *}$ & 1.699 & 1.406 & 2.053 \\
\hline
\end{tabular}




\section{Discussion}

MS is a group of abnormal metabolic disorders characterized by hypertension, insulin resistance, hyperglycemia, dyslipidemia, and central obesity. It is a major cause of morbidity and mortality [9]. In our study we divide participant into two groups according to the presence or absence of MS based on above mentioned criteria. Our study demonstrate that MS group have older age, higher systolic and diastolic blood pressure, TG level, waist circumference and BMI and lower level of Vitamin D and HDL and this are consistent with other studies [10-13] that concluded that MS is more prevalent in obese and elderly people. Our study demonstrated that was significant different between patients with and without Vitamin $\mathrm{D}_{3}$ deficiency as regard the presence of metabolic syndrome and this concordant with many studies $[14,15]$ that concluded that Vitamin $\mathrm{D}_{3}$ deficiency has a growing role in the pathogenesis of MS. Our study showed that Vitamin $D_{3}$ deficiency cases were significantly higher as regard Age, SBP, DBP, TG, FBS, WC and BMI. This in agreement with a study of Wieder-Huszla and his colleagues that concludes that Vitamin $\mathrm{D}_{3}$ deficiency was an independent factor for MS in the elderly [16]. Another study by Lee and his colleagues that found that lower Vitamin D level was associated with higher blood pressure and CVS risk [8]. Spearman correlation in our study revealed There was moderate negative correlation between Vitamin D3 deficiency and age, SBP, DBP, FBS, WC and BMI and positive weak correlation with HDL level. This was in agreement with many studies [14-16]. Interestingly, our study demonstrated that Vitamin $\mathrm{D}_{3}$ deficiency $<20 \mathrm{ng} / \mathrm{ml}$ and $\mathrm{BMI}>35$ were significant predictors for metabolic syndrome. This in agreement with a study of Wang and his colleagues that concluded that low Vitamin $\mathrm{D}_{3}$ concentration is an independent risk factor for M.S $[17,18]$.

Conclusion: Vitamin $\mathrm{D}_{3}$ level inversely correlates with the presence of metabolic syndrome in Egyptian Population.

\section{References}

1. Wu Y, Ding Y, Tanaka Y, Zhang W (2014) Risk factors contributing to type 2 diabetes and recent advances in the treatment and prevention. Int J Med Sci 11(11): 1185-200.

2. Grundy SM, Cleeman JI, Daniels SR, Donato KA, Eckel RH, et al. (2005) Diagnosis and management of the metabolic syndrome: An american heart association/national heart, lung, and blood institute scientific statement. Circulation 112(17): 2735-2752.

3. Ford ES, Ajani UA, McGuire LC, Liu S (2005) Concentrations of serum Vitamin D and the metabolic syndrome among US adults. Diabetes Care

\section{8(5): 1228-1230.}

4. Pereira-Santos M, Costa PR, Assis AM, Santos CA, Santos DB (2015) Obesity and Vitamin D deficiency: A systematic review and metaanalysis. Obes Rev 16(4): 341-349.

5. Martin T, Campbell RK (2011) Vitamin D and diabetes. Diabetes Spectr 24(2): 113-118.

6. Gagnon C, Daly RM, Carpentier A, Lu ZX, Shore-Lorenti C, et al. (2014) Effects of combined calcium and Vitamin D supplementation on insulin secretion, insulin sensitivity and $\beta$-cell function in multi-ethnic Vitamin D-deficient adults at risk for type 2 diabetes: A pilot randomized, placebo-controlled trial. PLoS One 9(10): e109607.

7. Li YC, Qiao G, Uskokovic M, Xiang W, Zheng W, Kong J (2004) Vitamin D: A negative endocrine regulator of the renin-angiotensin-sin system and blood pressure. J Steroid Biochem Mol Biol 89-90(1-5): 387-392.

8. Lee JH, O’Keefe JH, Bell D, Hensrud DD, Holick MF (2008) Vitamin D deficiency: An important, common, and easily treatable cardiovascular risk factor?. J Am Coll Cardiol 52(24): 1949-1956.

9. Cornier MA (2008) The metabolic syndrome. Endocr Rev 29(7): 777822.

10. Al-Shoumer KA, Al-Essa TM (2015) Is there a relationship between Vitamin D with insulin resistance and diabetes mellitus?. World J Diabetes 6(8): 1057.

11. Hyppönen E, Boucher BJ (2018) Adiposity, Vitamin D requirements, and clinical implications for obesity-related metabolic abnormalities. Nutr Rev 76(9): 676-692.

12. Araghi SO (2015) BMI and body fat mass is inversely associated with Vitamin D levels in older individuals. J Nutr Health Aging 19(10): 980985.

13. Vimaleswaran KS (2013) Causal relationship between obesity and Vitamin D status: Bi-directional Mendelian randomization analysis of multiple cohorts. PLoS Med 10(2): e1001383.

14. Strange RC, Shipman KE, Ramachandran S (2015) Metabolic syndrome: A review of the role of Vitamin $D$ in mediating susceptibility and outcome. World J Diabetes 6(7): 896.

15. Awad AB, Alappat L, Valerio M (2012) Vitamin D and metabolic syndrome risk factors: Evidence and mechanisms. Crit Rev Food Sci Nutr 52(2): 103-112.

16. Janssen HC, Samson MM, Verhaar HJ (2002) Vitamin D deficiency, muscle function, and falls in elderly people. Am J Clin Nutr 75(4): 611-615.

17. Wieder-Huszla S, Jurczak A, Szkup M (2019) Relationships between Vitamin $\mathrm{D}_{3}$ and metabolic syndrome. Int J Environ Res Public Health 16(2): 175 .

18. Wang CM, Chang CS, Chang YF (2018) Inverse relationship between metabolic syndrome and 25-hydroxy Vitamin D concentration in elderly people without Vitamin D deficiency. Sci Rep 8(1): 17052. 